\title{
Adipose stromal cells primed with hypoxia and inflammation enhance cardiomyocyte proliferation rate in vitro through STAT3 and Erk $1 / 2$
}

Ewa Przybyt, Guido Krenning, Marja GL Brinker and Martin C Harmsen*

\begin{abstract}
Background: Experimental clinical stem cell therapy has been used for more than a decade to alleviate the adverse aftermath of acute myocardial infarction (aMl). The post-infarcted myocardial microenvironment is characterized by cardiomyocyte death, caused by ischemia and inflammation. These conditions may negatively affect administered stem cells. As postnatal cardiomyocytes have a poor proliferation rate, while induction of proliferation seems even more rare. Thus stimulation of their proliferation rate is essential after aMI. In metaplastic disease, the proinflammatory cytokine interleukin-6 (IL-6) has been identified as potent mediators of the proliferation rate. We hypothesized that IL-6 could augment the proliferation rate of (slow-)dividing cardiomyocytes.
\end{abstract}

Methods: To mimic the behavior of therapeutic cells in the post-infarct cardiac microenvironment, human Adipose Derived Stromal Cells (ADSC) were cultured under hypoxic $\left(2 \% \mathrm{O}_{2}\right)$ and pro-inflammatory conditions (IL-1 $\beta$ ) for 24h. Serum-free conditioned medium from ADSC primed with hypoxia and/or IL-1 $\beta$ was added to rat neonatal cardiomyocytes and adult cardiomyocytes (HL-1) to assess paracrine-driven changes in cardiomyocyte proliferation rate and induction of myogenic signaling pathways.

Results: We demonstrate that ADSC enhance the proliferation rate of rat neonatal cardiomyocytes and adult HL-1 cardiomyocytes in a paracrine fashion. ADSC under hypoxia and inflammation in vitro had increased the interleukin6 (IL-6) gene and protein expression. Similar to conditioned medium of ADSC, treatment of rat neonatal cardiomyocytes and HL-1 with recombinant IL-6 alone also stimulated their proliferation rate. This was corroborated by a strong decrease of cardiomyocyte proliferation after addition of IL-6 neutralizing antibody to conditioned medium of ADSC. The stimulatory effect of ADSC conditioned media or IL-6 was accomplished through activation of both Janus Kinase-Signal Transducer and Activator of Transcription (JAK/STAT) and Mitogen-Activated Protein (MAP) kinases (MAPK) mitogenic signaling pathways.

Conclusion: ADSC are promising therapeutic cells for cardiac stem cell therapy. The inflammatory and hypoxic host post-MI microenvironment enhances the regenerative potential of ADSC to promote the proliferation rate of cardiomyocytes. This was achieved in paracrine manner, which warrants the development of ADSC conditioned medium as an "of-the-shelf" product for treatment of post-myocardial infarction complications.

Keywords: Myocardial infarction, Hypoxia, Inflammation, ADSC, Interleukin-6, Cardiomyocyte Proliferation, STAT3, Erk1/2

\footnotetext{
* Correspondence: m.c.harmsen@umcg.nl

University Medical Center Groningen, Department of Pathology and Medical Biology, Cardiovascular Regenerative Medicine Research Group (CAVAREM), Department of Pathology and Medical Biology, University of Groningen, Hanzeplein 1 (EA11), Groningen, GZ 9713, The Netherlands
} 


\section{Introduction}

Postnatal cardiomyocytes (CM) have a limited proliferation rate that does not suffice to replenish the $\mathrm{CM}$ that are massively lost after Myocardial Infarction (MI). During human life span approximately half of the cardiomyocytes are replaced $[1,2]$. This indicates that there is a significant level of physiological proliferation of cardiomyocytes. Thus, novel therapies that promote the proliferation of $\mathrm{CM}$ after acute Myocardial Infarction (aMI) may alleviate postinfarct complications such as heart failure.

Over the past decade, mesenchymal stem cells (MSC) emerged as promising candidates for cardiac therapy. Stem cells and progenitor cells from sources that vary from bone marrow to adipose tissue and the heart itself have shown to be beneficial in animal models of aMI and in clinical trials [3-5]. The current dogma is that stem cells act primarily through paracrine intervention in the damaged cardiac microenvironment i.e. through secretion of trophic factors [6,7]. The secretion profile and the fate of administrated cells change upon a host microenvironment. Current research on preconditioning BM-MSC with the hypoxic and the inflammatory factors found in post-MI microenvironment improve the cardioprotective outcome of the therapeutic cells [8-10]. Thus priming Adipose tissue-derived stem cells (ADSC) for the treatment of MI with hypoxic and inflammatory conditions might result in the improvement of cardiac function.

ADSC belong to the family of MSC and are derived from the adipose vascular stromal fraction as fibroblastic, spindle-shaped, plastic adherent cells and co-express several mesenchymal markers such as CD105, CD90, CD44, CD29 or CD73 [11,12]. In vitro, ADSC secrete a plethora of factors that are cytoprotective, promote angiogenesis and induce proliferation of various cell types [13-15]. Indeed, in animal models of myocardial infarction, the intramyocardial administration of ADSC improved cardiac remodeling and function [16,17]. Yet, the influence of administered stem cells on the proliferation rate of cardiomyocytes is poorly studied.

In damaged tissues, interleukin-6 (IL-6) is both cytoprotective and anti-apoptotic $[18,19]$. However, during the late post-MI healing phase IL-6 is upregulated in the myocardium. This chronic exposure to IL- 6 activates as a compensatory hypertrophic reaction of the surrounding cardiac tissue and may contribute to cardiac fibrosis. IL-6 acts as a mitogen on several cell types, e.g. on hepatocytes during liver regeneration. Furthermore, IL-6 facilitates healing of damaged skeletal muscle through mitotic stimulation of muscle progenitor cells [20,21]. IL-6 binds to the IL-6/gp130 receptor complex and activates the associated Janus Kinase (JAK), which phosphorylates, i.e. activates STAT3 (signal transduction and activator of transcription) to p-STAT3. The p-STAT3 translocates to the nucleus and initiates transcription of its responsive genes. STAT3 activation can also occur through cross-talk between other mitogenic signaling pathways, such as the mitogen activated protein kinase (MAPK) pathway [22]. One of the trophic factors readily secreted by ADSC is IL-6. Therefore, we hypothesized that IL- 6 secreted by ADSC could stimulate the rate of cardiomyocyte proliferation through JAK/STAT and MAPK-dependent pathways.

\section{Materials and methods \\ ADSC isolation and culture}

Human subcutaneous adipose tissue samples were obtained after liposuction surgery, which was donated upon informed consent of the healthy patients with BMI below 30 (Bergman Clinics, The Netherlands). Adipose tissue was stored at $4^{\circ} \mathrm{C}$ and processed within $24 \mathrm{~h}$ post surgery. Following extensive washing with PBS, the tissue was enzymatically digested with $0.1 \%$ Collagenase A, (Roche Diagnostic, Mannheim, Germany) 1:1 in PBS, containing $1 \%$ bovine serum albumine (BSA; SigmaAldrich, Boston, MA) at $37^{\circ} \mathrm{C}$ for $1 \mathrm{~h}$. Digested tissue was washed with PBS, 1\% BSA to remove the adipocytes and lipid content. The cell pellet was resuspended in PBS, 1\% BSA and subjected to Lymphoprep (Axis-Shield PoC, Oslo, Norway) density gradient centrifugation. The cells from the interface were collected and washed with PBS, 1\% BSA and resuspended in DMEM (Lonza Biowhittaker, Verviers, Belgium), 10\% FBS (Thermo Scientific, Hemel Hempstead, UK), $100 \mathrm{U} / \mathrm{mL}$ penicillin, $100 \mathrm{mg} / \mathrm{mL}$ streptomycin (Gibco, Invitrogen, Carlsbad, $\mathrm{CA}$ ) and $2 \mathrm{mM}$ L-glutamine (Lonza Biowhittaker, Verviers, Belgium). Cells were seeded in culture flasks at $4 \times 10^{4} / \mathrm{cm}^{2}$, expanded till Passage 3 and used for experiments. The use of liposuction material as source of ADSC was approved by of the local Ethics Committee of University Medical Centre Groningen, given the fact that it was considered the use of anonymised waste material. Yet, for every one of these anonymous donations the clients gave their consent after information.

\section{Cardiomyocytes isolation and culture}

Rat neonatal cardiac tissues were collected and kept in a head-over-head rotator at $4^{\circ} \mathrm{C}$ in trypsin (Gibco, Invitrogen, Carlsbad, CA) overnight. Afterwards, the tissues were enzymatically digested with $550 \mathrm{U}$ of Collagenase A, (Roche Diagnostic, Mannheim, Germany) and filtered through $70 \mu \mathrm{m}$ cell straine into the cold FCS solution (Gibco, Invitrogen, Carlsbad, CA). The cell suspension was resuspended in DMEM (Lonza Biowhittaker, Verviers, Belgium), 10\% FCS (Gibco, Invitrogen, Carlsbad, CA), $100 \mathrm{U} / \mathrm{mL}$ penicillin, $100 \mathrm{mg} / \mathrm{mL}$ streptomycin (Gibco, Invitrogen, Carlsbad, CA) and $2 \mathrm{mM}$ L-glutamine (Lonza Biowhittaker, Verviers, Belgium). Fibroblasts were depleted through plastic adhesion, non-adhered cells i.e. 
cardiomyocytes were re-seeded at 20,000 cells $/ \mathrm{cm}^{2}$ in fibronectin-coated flasks ( $25 \mu \mathrm{g} / \mathrm{ml}$, Harbor Bio-products, Noordwood, MA). Animal experiments, i.e. the use of neonatal rat heart for the isolation of cardiomyocytes was approved by the local committee for animal experiments of the Amsterdam University Medical Centre. Animal experimentation was approved by the local committee for care and use of laboratory animals and performed according to strict governmental and international guidelines. The investigation conformed to Guide for the Care and Use of Laboratory Animals published by the US National Institutes of Health (NIH Publication No. 85-23, revised 1996).

HL-1 murine cardiomyocytes were a kind gift of Dr. William C. Claycomb (Department of Biochemistry and Molecular Biology, Louisiana State University Health Science Center, New Orleans, LA, USA). Cells were maintained in fibronectin-coated flasks in Claycomb expansion medium (Sigma-Aldrich, Boston, MA,) supplemented with $10 \%$ FBS (Sigma-Aldrich, Boston, MA), $0.1 \mathrm{mM}$ norepinephrine (Sigma-Aldrich, Boston, MA), $100 \mathrm{U} / \mathrm{mL}$ penicillin, $100 \mathrm{mg} / \mathrm{mL}$ streptomycin (Gibco, Invitrogen, Grand Island, NY) and 2mM L-glutamine (Lonza Biowhittaker, Verviers, Belgium) and kept semi-confluent at all times.

\section{Experimental culture conditions}

Prior to co-cultures of ADSC and rat neonatal cardiomyocytes ( $\mathrm{rnCM}$ ) the cells were labeled with the CFDA SE (green) and CM-DiI (red) respectively according to the manufacturer 's instructions (both Molecular probes, Invitrogen, Grand Island, NY). Co-cultures of ADSC and HL-1 cardiomyocytes were done after lentivirus tagging with resp. lentiviruses encoding eGFP and dTomato. Briefly, on the day of transduction, cells were plated at $1 \times 10^{6}$ cells/well in serum-free growth medium containing $5 \mu \mathrm{g} / \mathrm{ml}$ polybrene (Sigma-Aldrich, Boston, MA). Following overnight incubation, medium was replaced with normal growth medium containing 10\% FBS. The medium of HL-1 cells was changed once per $24 \mathrm{~h}$ while ADSC medium was replenished three times a week. At five days post-transduction, cells were FACS sorted based on expression of eGFP or dTOMATO to obtain pure cell population. To determine the influence of the ADSC density on cardiomyocyte proliferation, ADSC were treated with $10 \mu \mathrm{g} / \mathrm{ml}$ mitomycin-C (Sigma-Aldrich, Boston, MA) for $3 \mathrm{~h}$, followed by extensive washing with PBS prior the co-culture with rnCM and HL-1 cells. The ADSC cell ratios plated in co-culture conditions varied from 1:1 to $1: 3$ for $\mathrm{rnCM}$, while keeping the $\mathrm{rnCM}$ at 20,000 cells $/ \mathrm{cm}^{2}$. The ADSC ratios in co-cultures with HL-1 cells varied from 1:1 to 1:4, while keeping the HL-1 cells at 6,000 cells $/ \mathrm{cm}^{2}$. Simultaneously, cells were labeled with $1 \mu \mathrm{M}$ BrdUrd-bromodeoxyuridine (Sigma-Aldrich, Boston, MA) for $6 \mathrm{~h}$ at the end of the experiment. In order to study the effect of the post-MI microenvironment on cardiomyocytes, rnCM and HL-1 cells and ADSC were cultured at ambient oxygen tension $21 \% \mathrm{O}_{2}$ (normoxia) or at $2 \% \mathrm{O}_{2}$, (hypoxia). At these oxygen tensions inflammation was mimicked by continuous treatment with TNF- $\alpha$ or IL-1 $\beta$ (both $10 \mathrm{ng} / \mathrm{ml}$ Peprotech, Rocky Hill, NJ) or none as a control for 24 and $48 \mathrm{~h}$ respectively. ADSC conditioned medium was collected after pre-treatment according to the experimental procedures for $24 \mathrm{~h}$. Subsequently, followed by medium replacement without the stimuli and conditioning in 0\% FBS Claycomb Medium for $24 \mathrm{~h}$.

\section{Gene transcript analysis}

ADSC were seeded in 12 well plates at 10,000 cells $/ \mathrm{cm}^{2}$ in DMEM and treated according to the experimental procedures. HL-1 cardiomyocytes were seeded in 12 well plates at 10,000 cells $/ \mathrm{cm}^{2}$ in $5 \%$ FBS Claycomb medium, afterwards cells were incubated with 10\% FBS (control) and $0 \%$ FBS Claycomb medium or $0 \%$ FBS ADSC conditioned medium for $24 \mathrm{~h}$ and treated according to the experimental procedures. Cells were harvested at the pre-determined time points and RNA was extracted using the Rneasy Mini Kit (Qiagen Inc., Valencia, CA) for ADSC and Trizol Reagent (Life technologies, Carlsbad, CA) method for HL-1 cells according to manufacturer 's protocol. Afterwards, $1 \mu \mathrm{g}$ of total RNA was reverse transcribed using the First Strand cDNA synthesis kit (Fermentas UAB, Vilnius, Lithuania) according to manufacturer 's instructions. The cDNA equivalent of $5 \mathrm{ng}$ RNA was used for amplification in 384-well microtiter plates in a TaqMAN ABI7900HT cycler (Applied Biosystem, Foster City, CA) in a final reaction volume of $10 \mu \mathrm{l}$ containing $5 \mu \mathrm{l}$ SyberGreen universal PCR Master Mix (BioRad, Richmond, CA) and 6 $\mu \mathrm{M}$ primer mix (forward and reverse). $6 \mu \mathrm{M}$ of mouse Beta-2 microglobulin and human GAPDH primer mix were used as a reference gene. Cycle threshold $\left(C_{\mathrm{T}}\right)$ values for individual reactions were determined using ABI Prism SDS 2.2 data processing software (Applied Biosystem, Foster City, CA). To determine the differences in expression, the $C_{T}$ values were normalized to reference gene using the $\Delta \Delta \mathrm{Ct}$ method, normalizing for the expression of the reference gene and related to the control treatment. All cDNA samples were amplified in duplicate. (Table 1)

\section{ELISA}

ADSC conditioned medium was collected and filtered through $0.2 \mu \mathrm{m}$ filter to remove any residual debris. To quantify the IL- 6 production by ADSC, collected media were assessed by enzyme-linked immunosorbent assay (ELISA) (R\&D Systems, Minneapolis, MN) according to manufacturer 's protocol. Absorbance values for individual 
Table 1 Primer sequence for qRT-PCR

\begin{tabular}{|c|c|c|}
\hline Mouse primer & Forward & Reverse \\
\hline IL-6 & 5'TTCCTCTGGTCTTCTGGAG-3' & 5'-TGAGGAATGTCCACAAACTG-3' \\
\hline gp80 & 5'-AAACAGTGTGGGAAGCAAGT-3' & 5'ATGGCTGATACCACAAGGTT-3' \\
\hline gp130 & 5'-AGCGTTGTGGAAATAGAAGC-3' & 5'-GGACTTCAGGTCATCTGGAC-3' \\
\hline Cyclin D1 & 5'-AGCTGGTGTTTGGAAGTAGG-3' & 5'-AAAAGCCTCCTGTGTGAGAC-3' \\
\hline Cyclin D2 & 5'-TTGCCATTTCTTTCCTCTC-3' & 5'-AGTGCTTCCCTTACCTCCTT-3' \\
\hline c-myc & 5'-GAGGAAACGACGAGAACAGT-3' & 5'-AGTGCTTCCCTTACCTCCTT-3' \\
\hline Bclx & 5'-CCCCTGCAATTAGCTTTCTA-3' & 5'-AGGCCAAGAGAACTGAGATG-3' \\
\hline B2M & 5'-AGAATGGGAAGCCGAACTA-3' & 5'-CCGTTCTTCAGCATTTGGAT-3' \\
\hline Human primer & Forward & Reverse \\
\hline IL-6 & 5'-ACTTGCCTGGTGAAAATCAT-3' & 5'-CAGGAACTGGATCAGGACTT-3' \\
\hline GAPDH & 5'-AGCCACATCGCTCAGACAC-3' & 5'-GCCCAATACGACCAAATCC-3' \\
\hline
\end{tabular}

reactions were determined using VersaMax ${ }^{\mathrm{TM}}$ Microplate Reader with SoftmaxPro 3.0 data processing software. To assure statistically relevant data, samples were run in triplicate from three independent donors.

\section{Immunoblot analysis}

Confluent rnCM or HL-1 cardiomyocyte cultures were serum-starved overnight. Subsequently, $50 \mu \mathrm{M}$ Stattic (STAT3 inhibitor) (Calbiochem, Darmstadt, Germany) or $10 \mu \mathrm{M}$ UO126 (MEK-1 inhibitor) (Promega, Madison, WI) and solvent controls were added to HL-1 cells for 2h. Next, rnCM or HL-1 cultures were treated with ADSC conditioned medium for $30 \mathrm{~min}$. Protein lysates from serum depleted, confluent cultures of HL- 1 cells were prepared in RIPA buffer (Thermo Scientific, Rockford, IL,) supplemented with $1 \%$ protease inhibitor cocktail and 1\% phosphatase inhibitors cocktail 2, 3 (Sigma-Aldrich, Boston, MA). Cell lysates $(20 \mu \mathrm{g})$ were run on $10 \%$ polyacrylamide electrophoresis gel and blotted onto nitrocellulose membrane according to standard protocol. Blots were blocked in Tris-buffered saline (TBS) containing 5\% BSA (Sigma-Aldrich, Boston, MA) for $1 \mathrm{~h}$. Subsequently, blots were incubated in TBS-1\% Tween containing 5\% BSA with primary antibodies to human p-STAT3 (Y705), STAT3 (Cell Signaling Technology, Beverly, MA), p-Erk1/2 (Thr 202/Tyr 204), Erk1/2 (42/44) (Cell Signaling Technology, Beverly, MA), diluted 1:1000, overnight. Afterwards, blots were washed and incubated with alkaline phosphataseconjugated antibodies to mouse or rabbit IgG, at the dilution 1:2000 for $1 \mathrm{~h}$. NBT/BCIP (Bio-Rad, VA) was used as a substrate for detection. Densitometric analysis was performed using Totallab 120 (Nonlinear Dynamic, Newcastle upon Tyne, England).

Immunofluorescence microscopy and image analysis rnCM and HL-1 cardiomyocytes were seeded semiconfluent onto polystyrene 8-chamber slides (Thermo
Scientific, Hemel Hempstead, UK). Subsequently, cells were serum-starved in serum-free Claycomb Medium overnight. Afterwards, samples were stimulated with 10 ng/ml IL-6 (Peprotech, Rocky Hill, NJ), conditioned media of ADSC and conditioned media of ADSC supplemented with IL-6 neutralizing antibody $(1.2 \mu \mathrm{g} / \mathrm{ml})$ or Mock IgG $(5.33 \mu \mathrm{g} / \mathrm{ml})$ as a control (all R\&D Systems, Minneapolis, $\mathrm{MN}$ ) for $24 \mathrm{~h}$. As a growth control, 10\% FBS Claycomb Medium was used. Simultaneously, cells were labeled with $1 \mu \mathrm{M}$ BrdUrd (Sigma-Aldrich, Boston, MA) for last $6 \mathrm{~h}$. Next, cells were fixed using $2 \%$ paraformaldehyde at room temperature for $20 \mathrm{~min}$. After extensive washing, cells were permeabilized with $0.5 \%$ Triton X-100 in PBS (Sigma-Aldrich, MA). Samples were treated with $0.7 \mathrm{M}$ $\mathrm{HCl}$ and $0.05 \%$ pepsin at $37^{\circ} \mathrm{C}$ and post-fixed with paraformaldehyde (4\% in PBS). Subsequently, samples were incubated with primary antibody sheep polyclonal biotinylated $\alpha$-BrdUrd (Abcam, Cambridge, UK) diluted 1:100 in PBS with 10\% goat serum (First Link Ltd, UK) overnight. Samples were washed extensively and incubated with secondary antibody Streptavidin-FITC for HL-1 cells and Streptavidin-Cy 3 for rnCM (Dako, Carpinteria, CA) diluted 1:400 in $3 \mu \mathrm{M}$ DAPI in PBS with $10 \%$ mouse serum (Sanquin, Amsterdam, The Netherlands) for 30 minutes.

To determinate the working mechanism of cardiomyocyte proliferation, serum-free cultured HL-1 cardiomyocytes were cultured in the presence of $50 \mu \mathrm{M}$ JAK1 inhibitor (AG490) or $50 \mu \mathrm{M}$ STAT3 inhibitor (Stattic) (Calbiochem, Darmstadt, Germany), $10 \mu \mathrm{M}$ RAS inhibitor (FTS) (Cayman Chemical Co., Ann Arbor, MI) or $10 \mu \mathrm{M}$ MEK inhibitor (U0126) (Promega, Madison, WI) and according controls with DMSO for 2h. Afterwards, cells were extensively washed with PBS and cultured in 5\% Claycomb medium or ADSC conditioned medium in the presence of $1 \mu \mathrm{M}$ BrdUrd for $6 \mathrm{~h}$. Next, samples were fixed using $2 \%$ paraformaldehyde and proceed with BrdUrd staining as mentioned above. 
Stained samples were extensively washed and proceed with Tissue FAXS analysis to quantify percentage of BrdUrd positive HL-1 cardiomyocytes. Examination was performed by immunofluorescent microscopy using a Leica DMRXA microscope and Leica software (Leica Microsystems), and further quantification was performed by TissueFAXS using a Zeiss AxioObserver. Z1 microscope and TissueQuest cell analysis software (TissueGnostics).

\section{Statistics}

All the data are presented as a means +/- SEM and were analysed by GraphPad Prism (version 5, GraphPad Software Inc.). Statistical significance was determined using one-way ANOVA with Bonferroni post hoc analysis. Values of $\mathrm{p}<0.05$ were considered statistically significant.

\section{Results}

ADSC promote the rate of cardiomyocyte proliferation in direct co-culture

We determined whether ADSC enhance the rate of cardiomyocyte proliferation in direct co-culture. In a 1:1 ratio, mitomycin-C-treated ADSC enhanced proliferation rate of rnCM 1.4-fold compared rnCM cultures alone $(p<0.05$, Figure 1A, F). Higher ratios (1:3) of ADSC had no significant benefit $(\mathrm{p}<0.05$, Figure $1 \mathrm{~A}, \mathrm{~F})$. At the $1: 1$ ratio, the rnCM density increased 2.5 -fold, yet at 3 -fold

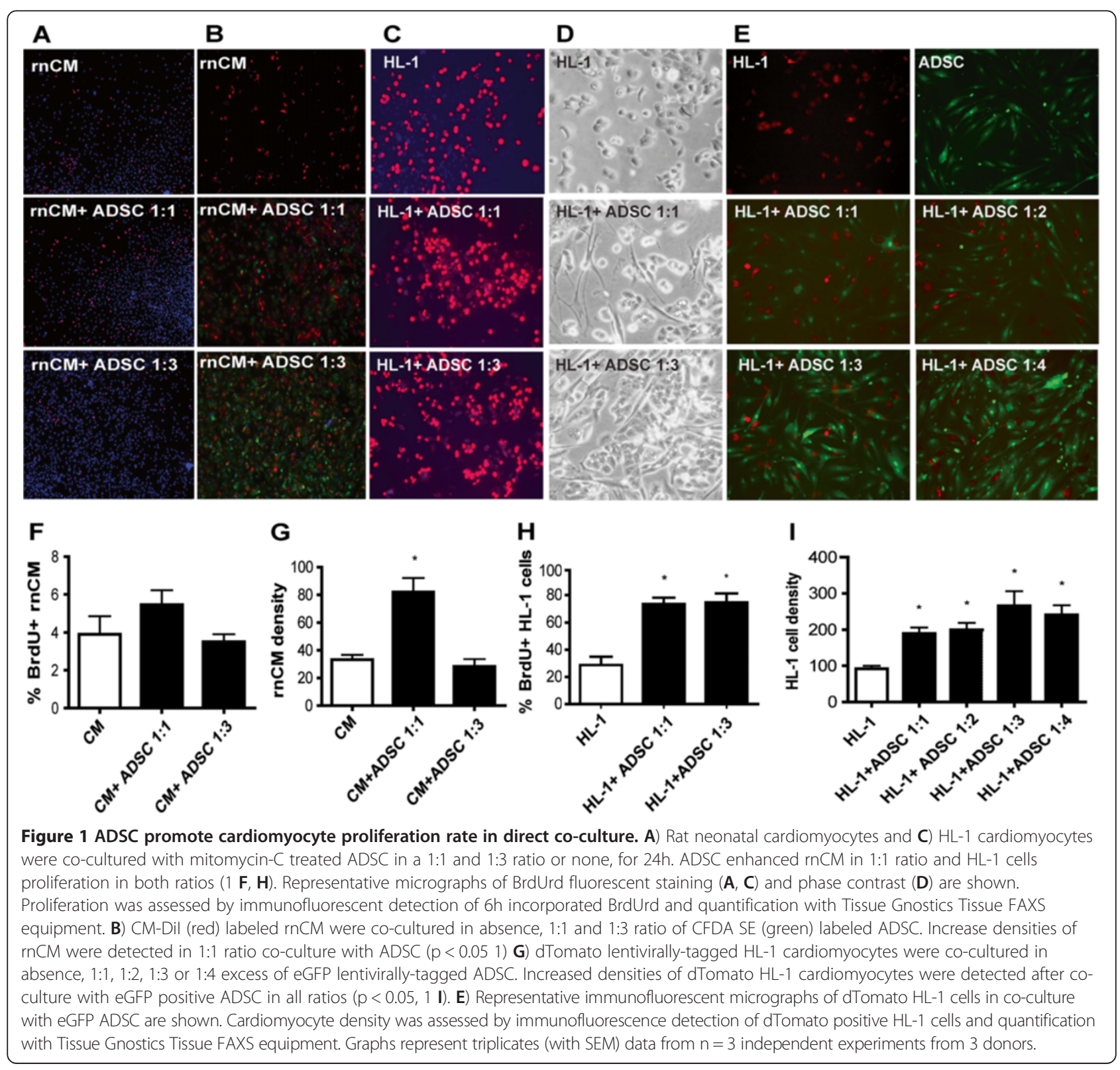


excess of ADSC increases of rnCM were minimal $(\mathrm{p}<0.05$, Figure $1 \mathrm{~B}, \mathrm{G})$.

As preparations of neonatal cardiomyocytes comprise are heterogeneous, we also assessed our findings with rnCM in the murine cardiomyocyte cell line HL-1. The proliferation rate of HL-1 cardiomyocytes was dramatically reduced by serum starvation and served to assess changes in the rate of proliferation by ADSC. HL-1 cardiomyocytes were co-cultured with ADSC in ratios $1: 1$ to $1: 4$. ADSC were pre-treated with mitomycin- $C$ to induce cell cycle arrest. This allowed for the quantification of BrdUrd incorporation in actively proliferating HL-1 cardiomyocytes. ADSC significantly enhanced the rate of proliferation of HL-1 cardiomyocytes by $45 \%$ and $46 \%$ in $1: 1$ and $1: 3$ ratios compared to HL-1 cardiomyocyte alone $(\mathrm{p}<0.05$, Figure $1 \mathrm{C}, \mathrm{H})$. To investigate if various ratios of ADSC influence cardiomyocyte density, lentivirally eGFP-tagged ADSC (green) were co-cultured with lentivirally dTomato-tagged HL-1 cardiomyocytes (red). The HL-1 cell density doubled in a 1:1 and 1:2 ratio and further increased in a 1:3 and 1:4 ratio compared to HL-1 cardiomyocytes alone ( $\mathrm{p}<0.05$, Figure 1B, D). ADSC enhanced HL-1 cardiomyocyte proliferation rate in all ratios, no significant differences were found between various ratios of ADSC to HL-1 cardiomyocytes $(\mathrm{p}<0.05$, Figure $1 \mathrm{E}, \mathrm{I})$.

\section{Conditioned medium of ADSC promotes the rate of proliferation of HL-1 cardiomyocytes}

Possibly, secreted factors of ADSC could cause the enhanced proliferation rate of cardiomyocytes. The putative beneficial influence of conditioned media from ADSC was assessed on rnCM and HL-1 cardiomyocytes subjected to hypoxia ( $2 \%$ oxygen) and inflammation (TNF- $\alpha$ or IL-1 $\beta$ ) (Figure 2A, B). In serum-containing media, approximately $10 \%$ and $12 \%$ of the rnCM proliferated respectively under normoxia and hypoxia. Serum starvation reduced the rate of proliferating $\mathrm{rnCM}$ to approximately $8 \%$ irrespectively of additional inflammatory factors (TNF- $\alpha$ or IL-1 $\beta)(p<0.05$, Figure $2 A)$. Normoxic conditioned

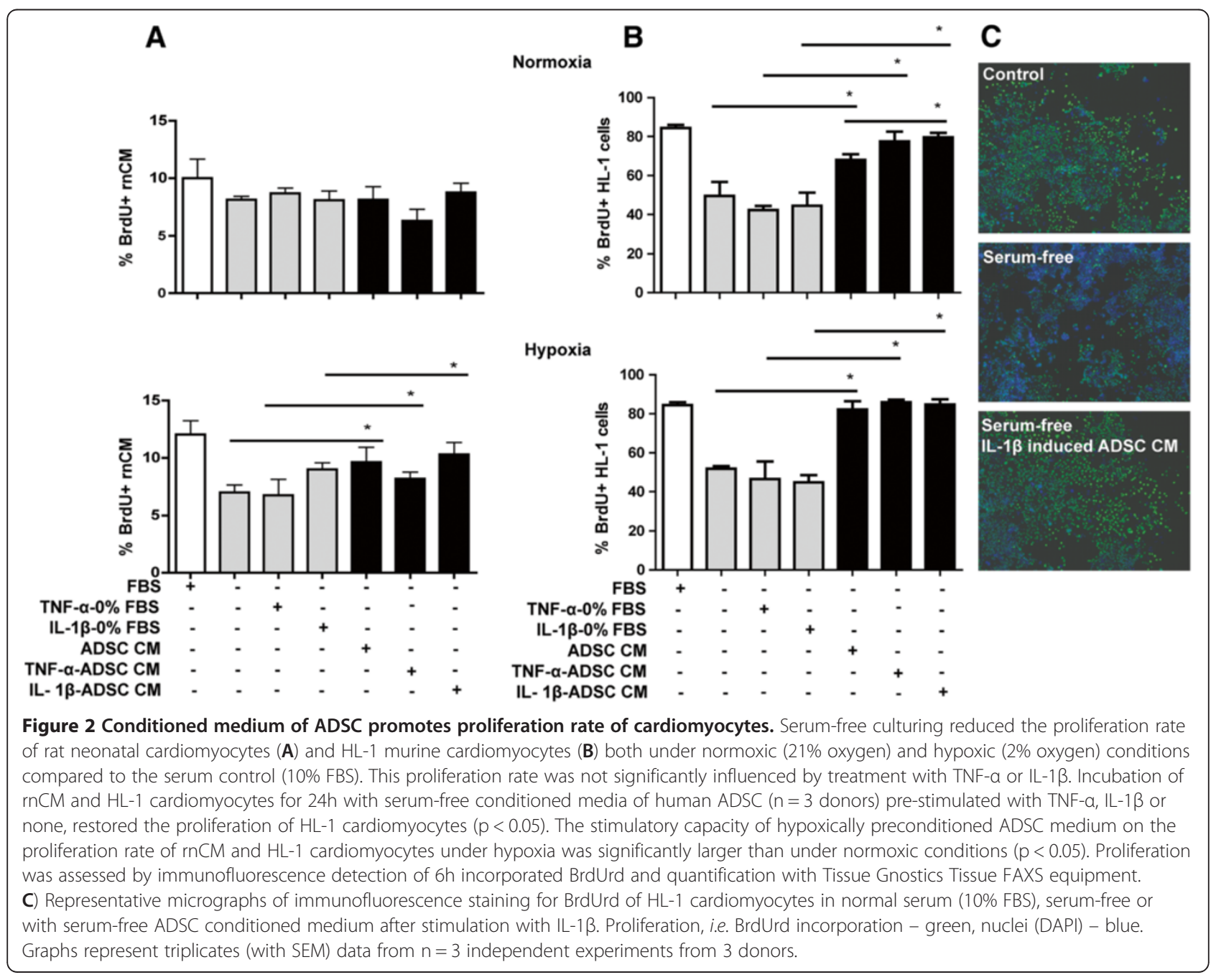


medium of ADSC did not change the rate of $\mathrm{rnCM}$ proliferation in high serum. Yet, after serum starvation the proliferation rate of $\mathrm{rnCM}$ increased 1.4-fold after treatment with normoxic conditioned medium of ADSC $(\mathrm{p}<0.05$, Figure $2 \mathrm{~A})$. The pre-conditioning of ADSC with TNF- $\alpha$ or IL- $1 \beta$ for the formation of the primed conditioned medium of ADSC resulted in respectively 1.2-fold increase in the proliferation rate of $\mathrm{rnCM}$ compared to TNF- $\alpha$ or IL-1 $\beta$ primed $\mathrm{rnCM}$ under hypoxia $(\mathrm{p}<0.05$, Figure $2 \mathrm{~A})$. To confirm the positive effect of the conditioned medium of ADSC on the enhancement of the cardiomyocyte proliferation rate, we performed the readout on the pure cardiomyocytes HL-1 cells.

In normal culture medium, approximately $85 \%$ of the HL-1 cardiomyocytes proliferated under both normoxic and hypoxic conditions. Serum starvation reduced the fraction of proliferating HL-1 cardiomyocytes almost two fold under normoxia or hypoxia. Treatment of serum-free HL-1 cardiomyocytes with TNF- $\alpha$ or IL-1 $\beta$ did not alter proliferation, irrespective of oxygen concentration. Serum-free-conditioned medium from normoxically cultured ADSC increased the proliferation rate of serum-free HL-1 cardiomyocytes by $18 \%$ compared to serum-free HL-1 cardiomyocytes control $(\mathrm{p}<0.05)$. The proliferation rate of HL-1 cardiomyocytes under normoxic conditions was even further stimulated $(35 \%, \mathrm{p}<0.05)$ upon incubation with conditioned medium from ADSC prestimulated with TNF- $\alpha$ or IL-1 $\beta$ compared to TNF- $\alpha$ or IL- $1 \beta$ stimulated serum-free HL-1 cardiomyocytes controls. The pro-inflammatory stimulation of ADSC with TNF- $\alpha$ or IL- $1 \beta$ to obtain primed ADSC conditioned medium ameliorated the cardiomyocyte proliferation rate as well. Furthermore, IL-1 $\beta$ primed conditioned medium of ADSC significantly increased $(12 \%, \mathrm{p}<0.05)$ the HL-1 proliferation rate compared to nonstimulated conditioned medium of ADSC. Moreover, conditioned medium from hypoxia cultured ADSC ameliorated the proliferation rate of cardiomyocytes even further in comparison to conditioned medium of normoxia cultured ADSC ( $31 \%$ vs. $18 \%$ increase, $\mathrm{p}<0.05)$. In addition, conditioned medium of hypoxia cultured ADSC in the presence of pre-stimulation with TNF- $\alpha$ or IL-1 $\beta$ showed only marginally improvement resulting in $40 \%$ increase in HL-1 cardiomyocyte proliferation rate $(\mathrm{p}<0.05)$.

\section{Hypoxia and pro-inflammatory mediators upregulate IL- 6 secretion by ADSC}

Treatment of ADSC with IL- $1 \beta$ for $24 \mathrm{~h}$ or $48 \mathrm{~h}$ induced respectively 53-fold and 31-fold upregulation of IL-6 gene expression level $(\mathrm{p}<0.05$, Figure $3 \mathrm{~A})$.
Under hypoxia, treatment of ADSC with IL- $1 \beta$ for 24 $\mathrm{h}$ and $48 \mathrm{~h}$ resulted in higher increase of IL- 6 gene expression, respectively by 95 -fold and 45 -fold ( $\mathrm{p}<0.05$, Figure 3B).

The level of secreted IL- 6 showed a similar pattern as the gene expression after stimulation of ADSC with IL$1 \beta$ (Figure 3C, D). Stimulation of ADSC with IL- $1 \beta$, induced a 500 -fold increase in IL-6 protein secretion within $24 \mathrm{~h}$, which decreased to approximately 200 -fold at $48 \mathrm{~h}$ both under normoxia and hypoxia $(\mathrm{p}<0.05$, Figure 3C, D).

\section{IL- 6 secreted by ADSC enhances the cardiomyocyte proliferation rate}

Stimulation with IL-6, increased the number of proliferating $\mathrm{rnCM}$ from $8 \%$ (serum free controls) to $9 \%$ $(\mathrm{p}<0.05$, Figure 3E). Addition of IL-6 neutralizing antibody to the IL- 6 treated $\mathrm{rnCM}$ reduced the number of proliferating cells to 7\% compared to IL-6 treated controls $(p<0.05$, Figure 3E). Stimulation of rnCM with the serum free ADSC conditioned medium resulted in increase of proliferating $\mathrm{rnCM}$ to $8.5 \%$ compared to serum free controls. Addition of IL-6 neutralizing antibody to the conditioned medium of ADSC resulted in significant decrease of proliferating rnCM to $7.4 \%$ ( $\mathrm{p}<0.05$, Figure $3 \mathrm{E})$.

Adult HL-1 cardiomyocytes were cultured in the presence of $10 \%$ serum. Under serum-free conditions, IL-6 and the conditioned medium of ADSC induced a $24 \%$ and $27 \%$ upregulation of the proliferation rate of HL-1 cardiomyocytes respectively, compared to HL-1 serumfree control $(\mathrm{p}<0.05$, Figure $3 \mathrm{~F})$. Addition of IL- 6 neutralizing antibodies to the IL-6 treated HL-1 cardiomyocytes reduced their proliferation rate by $42 \%$ $(\mathrm{p}<0.05$, Figure 3E) compared to IL-6 treated controls. Treatment of serum-free conditioned medium of ADSC with IL- 6 neutralizing antibodies also reduced the rate of HL-1 cardiomyocyte proliferation rate by $13 \%$ compared to conditioned medium of ADSC $(\mathrm{p}<0.05$, Figure 3F).

\section{Conditioned medium of ADSC increase cell cycle progression gene expression profile in HL-1 cardiomyocytes}

Cell cycle progression requires activation of cyclin complexes and G1/S phase transition and associates with increased expression of $\mathrm{c}-\mathrm{Myc}$, while anti-apoptotic genes such as Bclx are upregulated. Adult HL-1 cardiomyocytes were cultured in the presence of $10 \%$ serum. Serum-free HL-1 cardiomyocytes were cultured under normoxia and hypoxia in the presence of IL-6 or IL-1 $\beta$ primed conditioned medium of ADSC. Stimulation of HL-1 cardiomyocytes with the conditioned medium of ADSC from normoxia and IL-1 $\beta$ primed resulted in increased gene expression of cyclin D1 and 


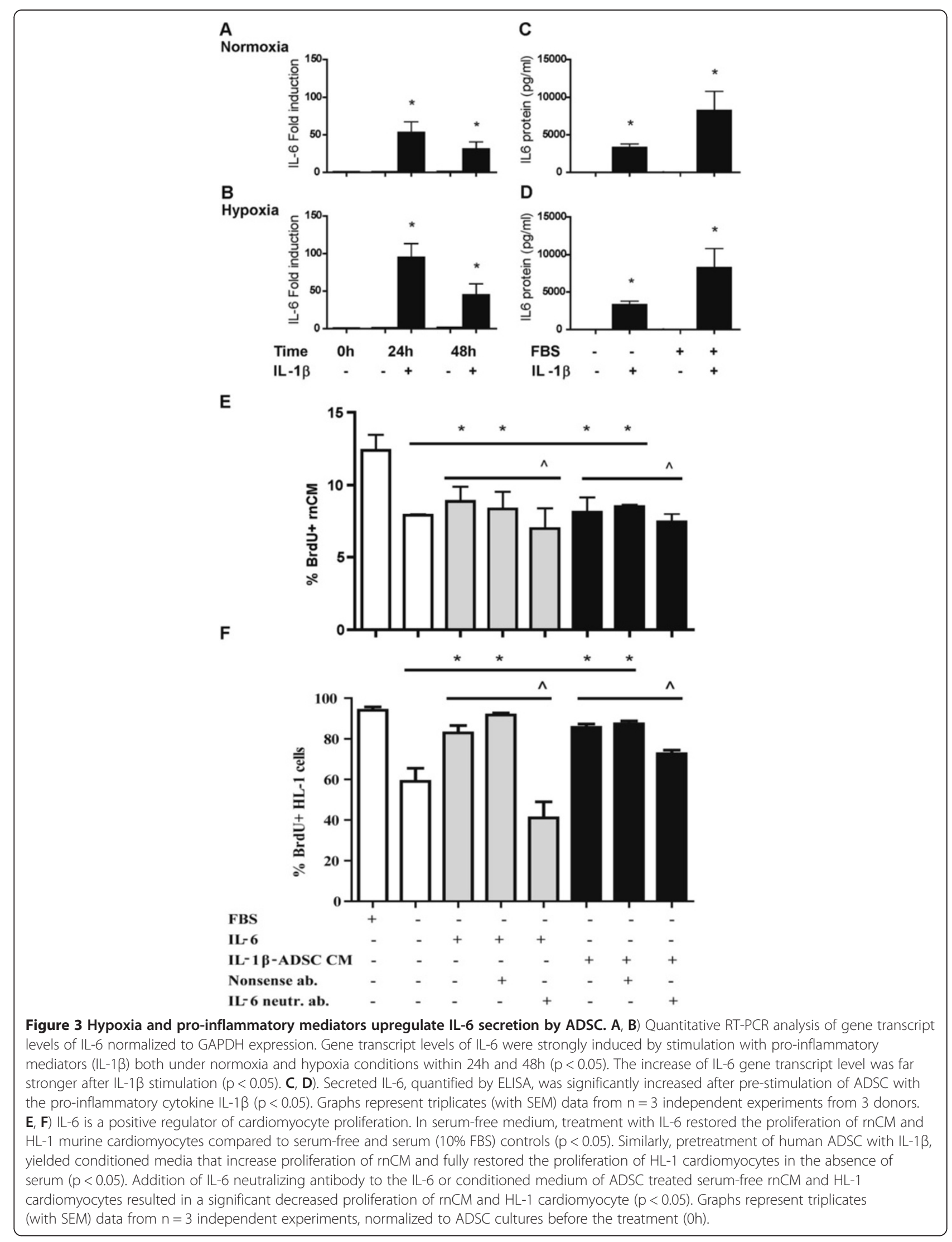


cyclin D2 compared to serum-free HL-1 cells, yet not significant $(p<0.05$, Figure 4A). Hypoxia and IL-1 $\beta$ primed conditioned medium from ADSC resulted in significant increase in the gene expression of cyclin D1 and cyclin D2 by respectively 1.2-fold and 1.3-fold increase compared to serum-free HL- 1 cells ( $p<0.05$, Figure 4B). Stimulation of HL-1 cardiomyocytes with IL-6 both under normoxia and hypoxia did not significantly affected the gene expression of cyclin D1 and cyclin D2 $(\mathrm{p}<0.05$, Figure $4 \mathrm{~A}, \mathrm{~B})$. The elevated gene expression of cyclin D1 and cyclin D2, followed the significant increase of c-myc gene expression in HL-1 cells. Stimulation of HL-1 cells with conditioned medium of ADSC or IL-1 $\beta$ primed ADSC conditioned medium under normoxia resulted in significant increase of c-myc gene expression, respectively by 1.7 -fold and 2.2 -fold induction compared to control HL-1 cells ( $\mathrm{p}<0.05$, Figure 4A). Stimulation of HL-1 cardiomyocytes with hypoxia and hypoxia with IL-1 $\beta$ primed conditioned medium from ADSC resulted in significant increase in gene expression of c-myc, respectively by 1.2 -fold and 1.6-fold induction compared to control HL-1 cells $(\mathrm{p}<0.05)$. Addition of IL-6 to HL-1 cells resulted in significant increase of cmyc gene expression only under normoxia by 1.3 -fold compared to control HL-1 cells ( $p<0.05$, Figure 4A). IL-6 stimulation of HL-1 cells under hypoxia did not show significant change in $\mathrm{HL}-1$ gene expression of c-myc compare to serum-free HL-1 cells $(\mathrm{p}<0.05$, Figure 4B). Stimulation of HL-1 cardiomyocytes with ADSC conditioned medium or IL-6 did not change expression of the antiapoptotic gene Bclx in HL-1 cardiomyocytes either under normoxia or hypoxia compared to control HL-1 cells ( $p<0.05$, Figure 4A, B).

\section{Conditioned medium of ADSC increases autocrine IL- 6 gene expression in $\mathrm{HL}-1$ cardiomyocytes}

HL-1 cardiomyocytes were cultured in the absence of serum as a control. Stimulation of HL- cardiomyocytes with IL-6 under serum-free conditions did not effect the gene expression profile of IL-6, IL-6 receptor $\alpha$ (gp80) or IL-6 receptor $\beta$ (gp130) both under normoxia and hypoxia compared to a serum-free control $(\mathrm{p}<0.05$, Figure 5A, B). Addition of ADSC conditioned medium to HL-1 cells significantly increased gene expression of IL-6 by 4-fold under normoxia and 5.4-fold under hypoxia compared to a serum-free control $(\mathrm{p}<0.05$, Figure 5A, B). Correspondingly, stimulation of HL-1 cardiomyocytes with conditioned medium of ADSC

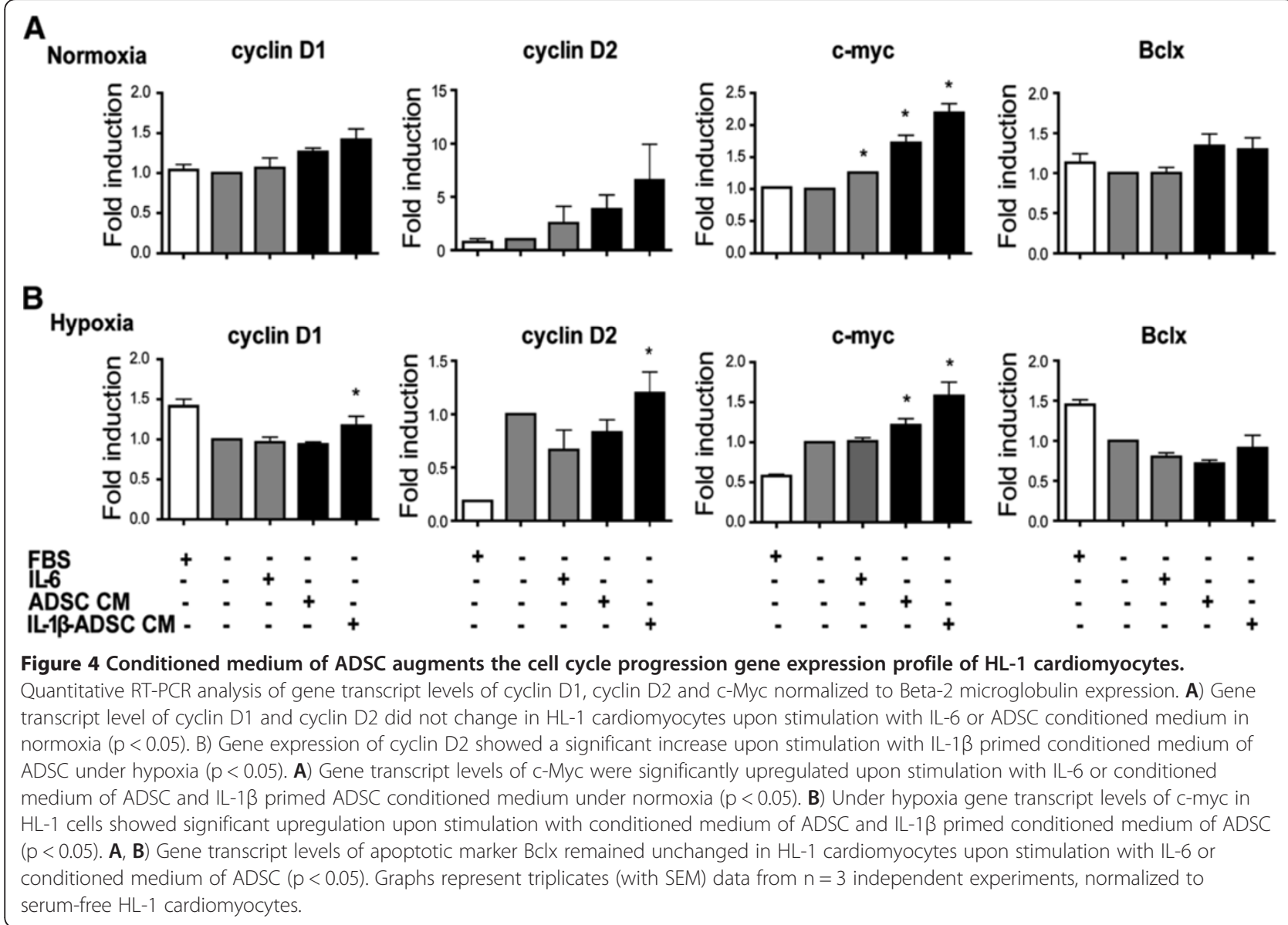




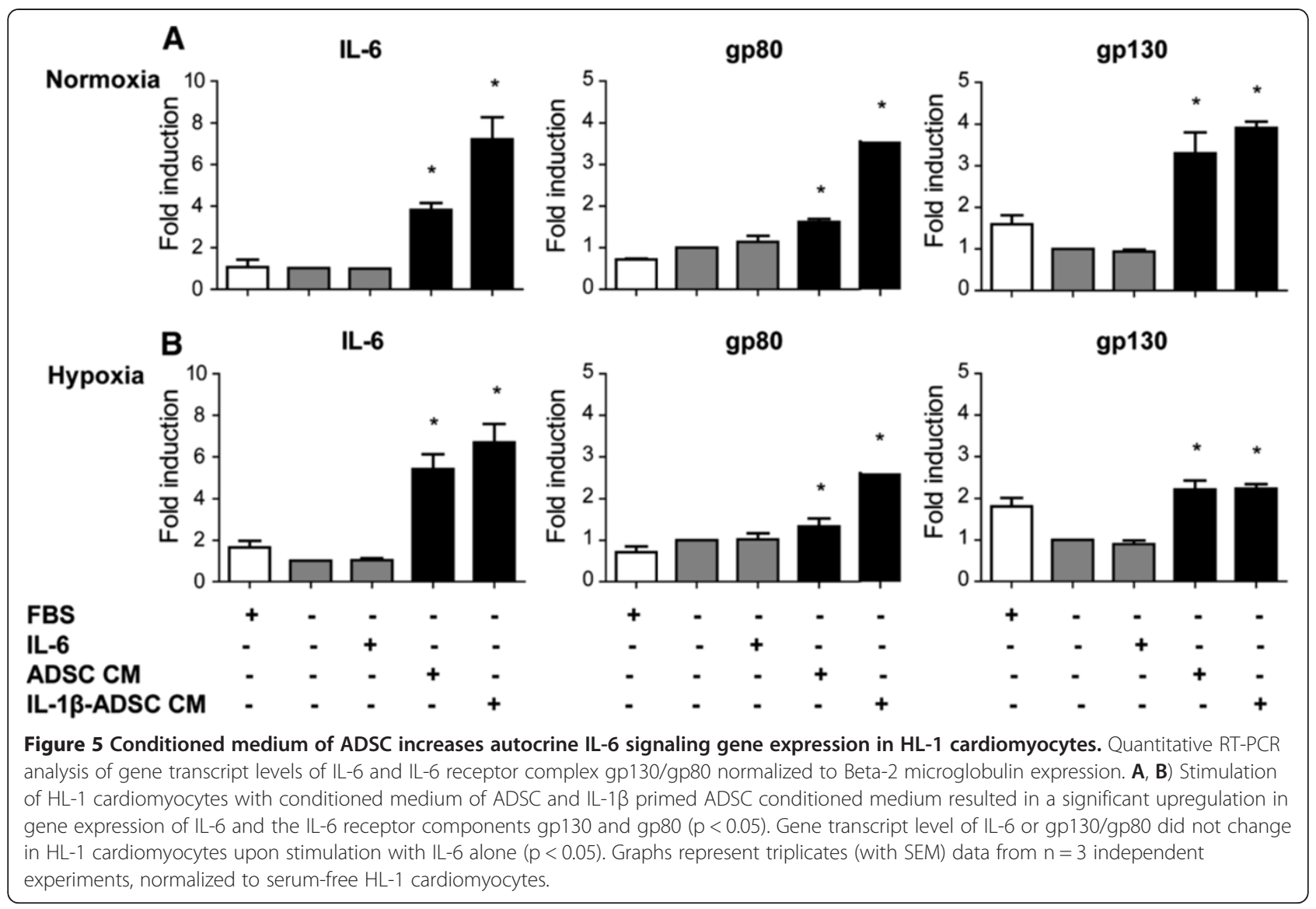

resulted in significant increase in gene expression of IL-6 receptor $\alpha$ (gp80) and $\beta$ (gp130) by respectively 1.6 and 3.3-fold under normoxia compared to a serum-free control $(\mathrm{p}<0.05$, Figure 5A) and 1.3 and 2.2-fold under hypoxia compared to a serum-free control $(\mathrm{p}<0.05$, Figure $5 \mathrm{~B}$ ). Addition of IL- $1 \beta$ primed ADSC conditioned medium to HL-1 cardiomyocytes resulted in higher increase of IL-6 gene expression, resulting in 7-fold increase under normoxia and hypoxia compared to a serum-free control $(\mathrm{p}<0.05$, Figure $5 \mathrm{~A}, \mathrm{~B})$. Stimulation of HL-1 cardiomyocytes with IL- $1 \beta$ primed conditioned medium of ADSC resulted in significant increase in gene expression of IL-6 receptor $\alpha$ (gp80) and $\beta$ (gp130) by respectively 3.5 and 3.9 -fold under normoxia compared to a serum-free control $(\mathrm{p}<0.05$, Figure $5 \mathrm{~A})$ and 2.6 and 2.2-fold under hypoxia compared to a serum-free control $(\mathrm{p}<0.05$, Figure 5B).

\section{ADSC conditioned medium-dependent signaling} pathways targeting the increased rate of cardiomyocyte proliferation

The phosphorylation of STAT3 in rnCM did not depend on the presence of serum (Figure 6A, B). Yet, serum free conditioned medium of ADSC resulted in activated STAT3 by 4-fold both under normoxia and hypoxia conditions in serum starved $\mathrm{rnCM}(\mathrm{p}<0.05$, Figure $6 \mathrm{~A}$, $\mathrm{B})$. The peak of activation of p-STAT3 was reached in rnCM by stimulation with conditioned medium of ADSC primed with IL-1 $\beta$ both under normoxia and hypoxia resulting in respectively 8.5 - and 10-fold increase compared to the serum free controls $(\mathrm{p}<0.05$, Figure $6 \mathrm{~A}$, $B)$. In rnCM Erk1/2 was strongly phosphorylated in the presence of serum $(\mathrm{p}<0.05$, Figure $6 \mathrm{~A}, \mathrm{C})$. Under serum free condition the phosphorylation of Erk1/2 was 2-fold decreased compared to serum control $(\mathrm{p}<0.05$, Figure $6 \mathrm{~A}, \mathrm{C})$. The stimulation of $\mathrm{rnCM}$ with the serum free conditioned medium of ADSC and the IL-1 $\beta$ primed conditioned medium of ADSC resulted in the strong activation of Erk1/2, reaching 1.5-fold increase in compare to serum free controls $(\mathrm{p}<0.05$, Figure $6 \mathrm{~A}, \mathrm{C})$ both under normoxia and hypoxia. The activation of Erk $1 / 2$ in $\mathrm{rnCM}$ by the serum free conditioned medium of ADSC was comparable to the level of phosphorylation in the rnCM stimulated with serum (Figure 6A, C). In HL-1 cardiomyocytes, STAT3 and Erk1/2 were both phosphorylated in the presence of serum. After $24 \mathrm{~h}$ of serum deprivation, the phosphorylation i.e. activation, of these transcription factors was only slightly reduced (Figure 6D-L). The phosphorylation of STAT3 was decreased by 3 -fold in the presence of the p-STAT3 


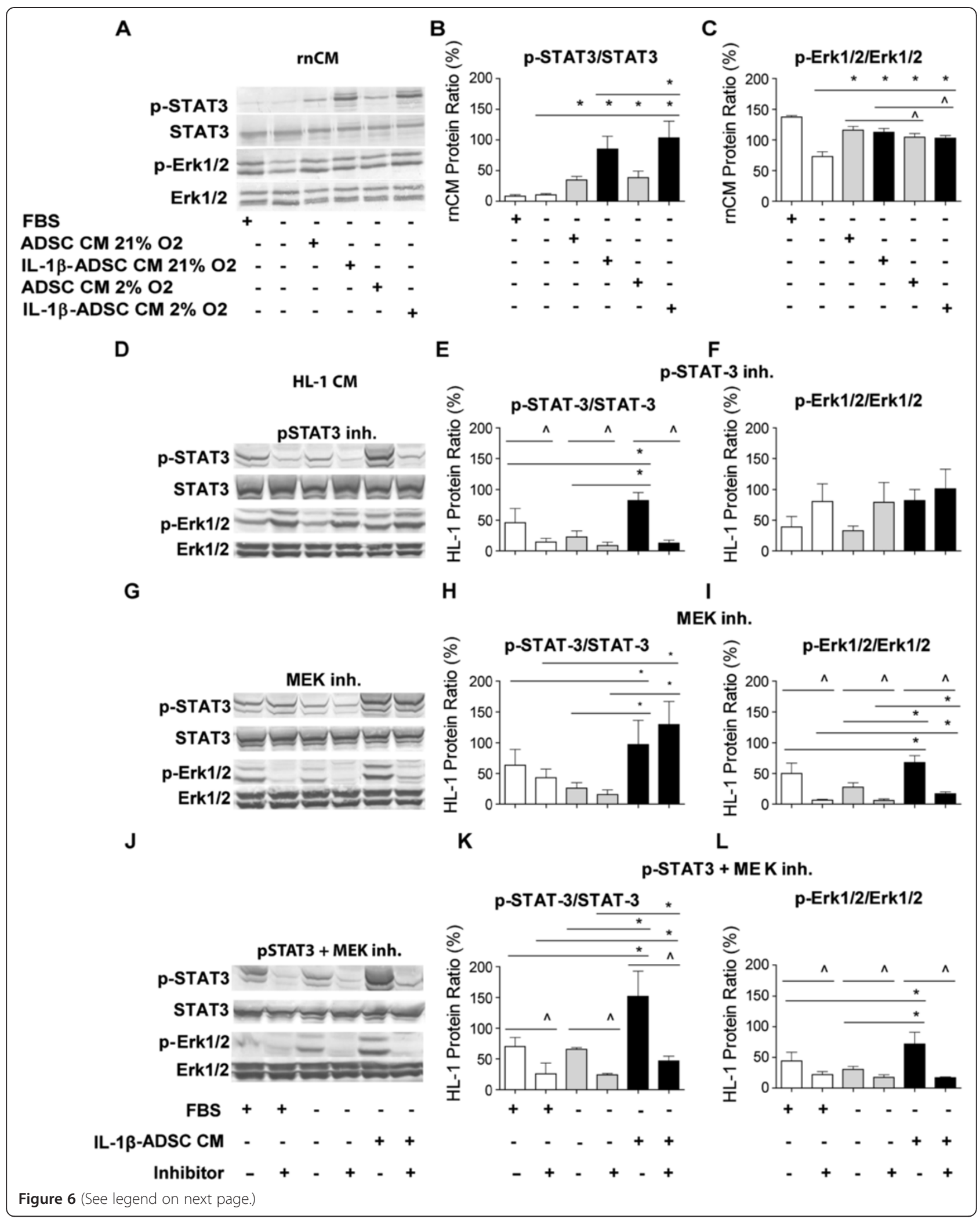


(See figure on previous page.)

Figure 6 ADSC conditioned medium-dependent signaling pathways targeting increase of HL-1 cardiomyocyte proliferation.

Representative examples of western blot analyses of phosphorylated STAT3 and phosphorylated Erk1/2 in A, B, C) rnCM stimulated with the conditioned medium of ADSC and IL-1 $\beta$ primed ADSC from normoxic and under hypoxic cultures. The stimulation of rnCM with the serum free conditioned medium of ADSC resulted in activation of STAT3 and Erk1/2. D, E, F) in HL-1 cardiomyocytes in the presence of STAT3

phosphorylation inhibitor (Stattic) G, H, I) MEK inhibitor (U0126) and J, K, L) both inhibitors (Stattic + U0126). Inhibition of STAT3 phosphorylation resulted in increased of Erk1/2 phosphorylation. Non-phosphorylated STAT3 and Erk1/2 levels did not change and indicate equivalent protein controls in all samples $(n=3)$.

inhibitor (Stattic) $(\mathrm{p}<0.05$, Figure 6D, E), while Erk1/2 phosphorylation was reduced by 8 - and 4 -fold with the MEK inhibitor (U0126) respectively in compare to the serum and serum-free controls $(\mathrm{p}<0.05$, Figure 6G, I). Remarkably, stimulation of $\mathrm{HL}-1$ cardiomyocytes with serum-free IL-1 $\beta$-stimulated-ADSC-conditioned medium resulted in a 2 -fold increase in phosphorylation of STAT3 and Erk1/2, that reached higher level than serum controls $(\mathrm{p}<0.05$, Figure 6D-L). Blocking of STAT3 phosphorylation resulted in reduced levels of phosphorylated STAT3 and 2-fold increased phosphorylation of Erk1/2 (Figure 6D, F). In contrast, activation of phosphorylated STAT3 did not depend on activation of Erk1/2 phosphorylation (Figure 6D-L). Simultaneous inhibition of JAK/STAT and MAPK signaling pathway resulted in reduced levels of phosphorylated STAT3 by 2.7 -fold and phosphorylated Erk1/2 by 2 -fold $(\mathrm{p}<0.05$, Figure 6J-L).

\section{ADSC-dependent signaling pathways targeting HL-1 cardiomyocyte proliferation rate}

In the presence of mitogenic factors such as serum and conditioned medium of ADSC, HL-1 cardiomyocytes showed an increase in proliferation $(25 \%$ and $24 \%$ respectively, $\mathrm{p}<0.05$, Figure $7 \mathrm{~A}, \mathrm{~B})$. In the presence of serum addition of inhibitors targeting upstream or downstream of JAK/STAT (JAK1 and STAT3) and MAPK (MEK1) signaling pathway resulted in a decreased proliferation rate of HL-1 cardiomyocytes ranging from 31 to $41 \%$ ( $<<0.05$, Figure $7 \mathrm{~A})$. Pretreatment of HL-1 cardiomyocytes with these inhibitors also reduced the mitogenic effect of conditioned medium of ADSC, observed as a significant decrease in the fraction of BrdUrd positive cells by 24 to $37 \%$ $(\mathrm{p}<0.05$, Figure 7B).

\section{Discussion}

In this study we show that Adipose Derived Stromal Cells (ADSC) enhance the proliferation rate of both primary $\mathrm{CM}$ and a CM cell line, in a paracrine manner and in direct co-culture in vitro. One of the main stimulators secreted by ADSC was IL-6. The in vitro hypoxic and pro-inflammatory preconditioning of ADSC i.e. mimicking the post-myocardial infarction microenvironment (ischemia and inflammation), strongly upregulated the
IL-6 production by ADSC and further augmented the stimulation of the proliferation of cardiomyocytes. The IL-6 stimulated cardiomyocyte proliferation was accomplished through activation of both Janus KinaseSignal Transducer and Activator of Transcription (JAK/ STAT) and Mitogen-Activated Protein (MAP) kinases (MAPK) mitogenic signaling pathways.

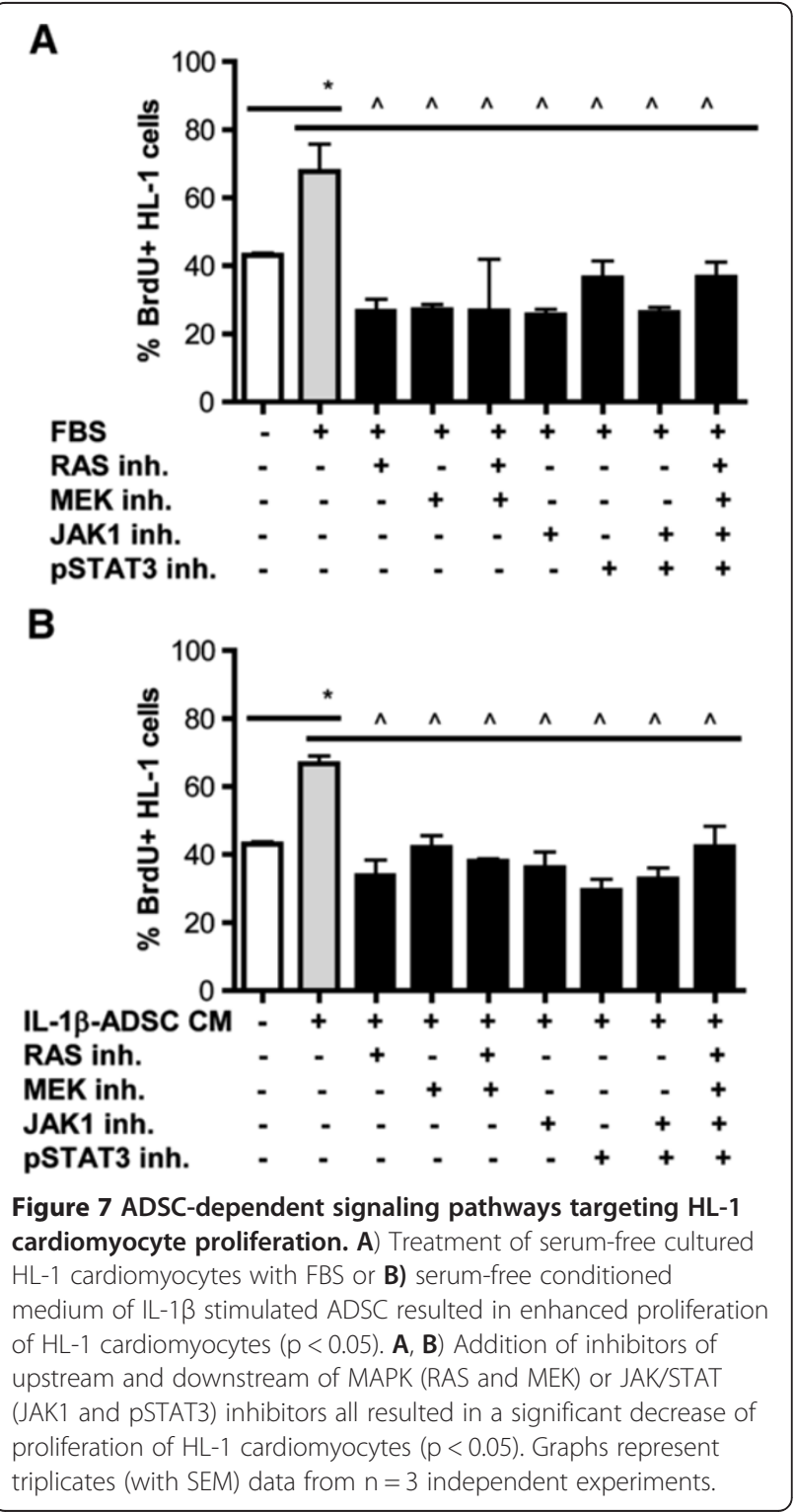


Stimulation of rat neonatal cardiomyocytes or HL-1 cardiomyocytes with conditioned medium of ADSC increased their proliferation rate. To mimic the behavior of therapeutic cells in the post-infarct cardiac microenvironment, we stimulated ADSC with hypoxia and pro-inflammatory mediators, which increased their production of IL-6. Remarkably, Efimenko and co-workers, showed that stimulation of MSC from bone marrow or adipose tissue with high concentrations of TNF- $\alpha$ did not alter their profile of pro-angiogenic mediators, which paradoxes to our finding that pro-inflammatory stimulation augmented regenerative potential of therapeutic cells [14]. The differences may be, that different stimuli (TNF versus IL-1) were used and different readouts, i.e. angiogenesis versus cardiomyocyte proliferation. Furthermore, our data indicate that hypoxia alone, but in particular together with a pro-inflammatory stimulus, augment CM proliferation by ADSC conditioned media too. This indicates that hypoxia can further augment the regenerative potential of ADSC. In contrast to current data, not only hypoxia may exert a beneficial effect on ADSC [15,23]. We found that inflammation had far stronger effect on the ADSC secretion profile. Although hypoxia itself did not alter IL-6 gene expression levels by ADSC, in combination with inflammatory mediators enhanced regenerative potential of ADSC.

Stimulation of rnCM and adult HL-1 cardiomyocytes with IL-6 resulted in an enhanced level of the cardiomyocyte proliferation rate. Targeting IL-6 with neutralizing antibodies against IL- 6 in the presence of IL- 6 or conditioned medium of ADSC resulted in decreased rate of cardiomyocyte proliferation. The blocking of IL-6 in ADSC conditioned medium only partially inhibited positive effect of ADSC conditioned medium on cardiomyocyte proliferation rate. This suggests that either conditioned medium of ADSC contains additional only mitogenic factors or that other factors promote rnCM and

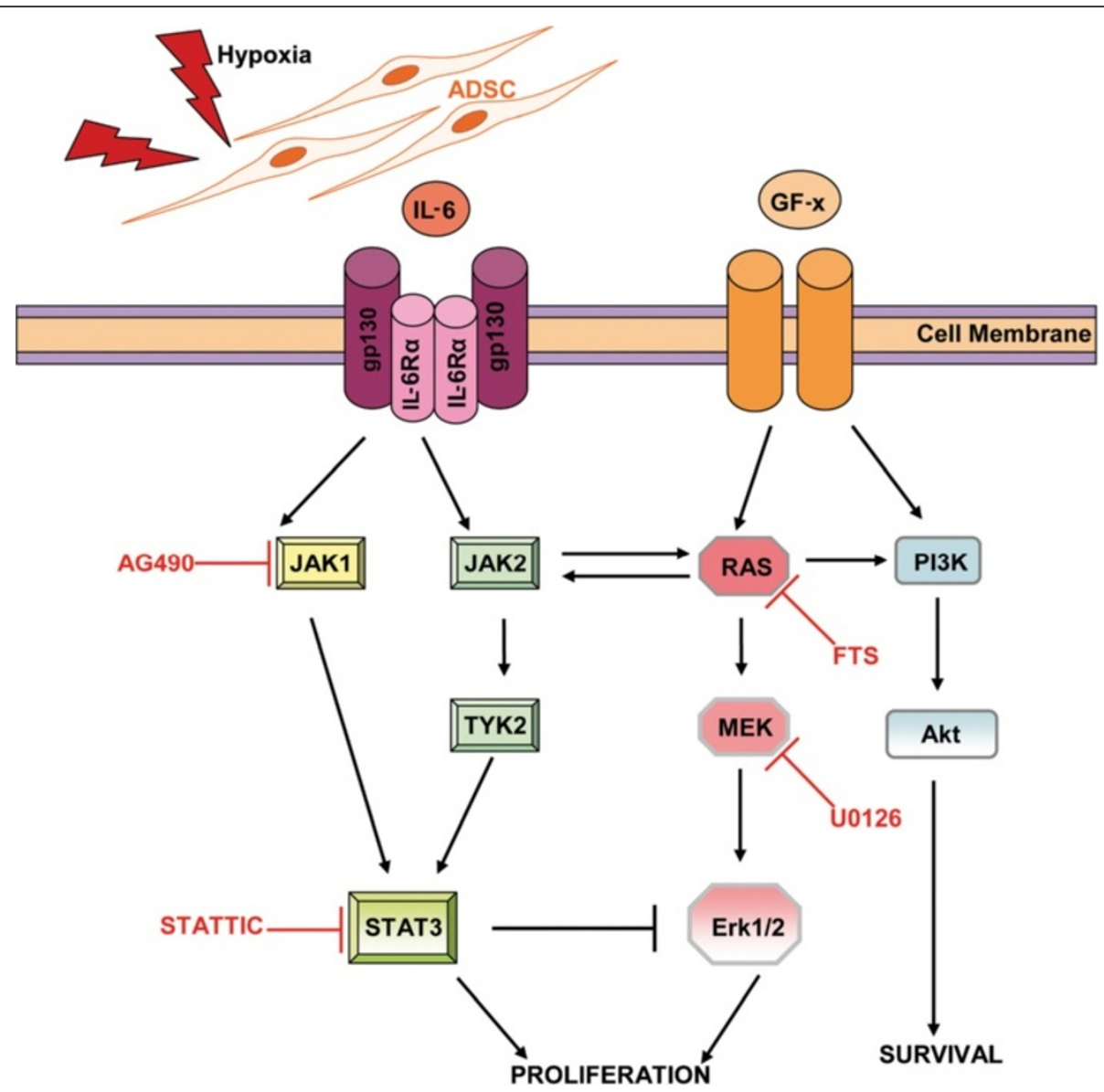

Figure 8 Schematic representation of proposed Adipose Stromal Cell-derived IL-6 signaling pathway. The ADSC-secreted cytokine IL- 6 and growth factors, which enhance the proliferation of cardiomyocytes through canonical signaling i.e. STAT3 activation and through noncanonical signaling i.e. Erk1/2 activation. The balance between STAT3 and Erk1/2 signaling is governed by STAT3, which can suppress Erk1/2 activation, through an unknown intermediate. In the absence of STAT3 signaling, IL-6-RAS-activated Erk1/2 can compensate for the potential loss of stimulatory effect on the proliferation on cardiomyocytes. 
HL-1 cardiomyocyte proliferation rate synergistically with IL-6.

This is corroborated by our observation that stimulation of HL-1 cardiomyocytes with conditioned medium of ADSC resulted in a significant increase of c-myc and IL-6 receptor complex gp130/gp80, while stimulation with IL-6 alone did not show significance gene expressions changes.

IL-6 signaling involves activation of downstream signaling of two major signaling pathways i.e. JAK/STAT and MAPK-Erk1/2 that are mitogenic in various cell types. Thus, we analyzed the significance of both of these pathways on cardiomyocyte proliferation rate. Our study identifies a previously uncharacterized function of conditioned medium of ADSC signaling in regulating cardiomyocyte proliferation. Stimulation of $\mathrm{rnCM}$ and HL-1 cardiomyocytes with conditioned medium of hypoxically and proinflammatory primed ADSC resulted in strong phosphorylation of STAT3 and Erk1/2, the downstream targets of JAK/STAT and MAPK activation (Figure 8).

Similarly, previous studies on skeletal muscle have shown that regular exercise causes damage that is followed by increased IL-6 level. The released IL-6 activates the JAK/STAT signaling pathway and augments repair of skeletal muscle [24]. Recent clinical therapies with postconditioning of the ischemic heart show beneficial effect on the reduction of the scar size due to the activation of STAT3 [25] and involvement of IL-6 in this process [26]. In addition, pro-inflammatory cytokines such as TNF- $\alpha$ related TWEAK or ligands from EGF family such as neuregulin and HB-EGF provided evidence for engagement MAPK in induction of the cardiomyocyte proliferation rate [27-29].

Conditioned medium of ADSC activated the downstream JAK1 and JAK2/TYK2 that lead to their target STAT3 $\mathrm{Tyr}^{705}$ phosphorylation in $\mathrm{rnCM}$ and HL-1 cardiomyocytes. Blocking of JAK1 with commonly used JAK/STAT inhibitor did not diminished the level of phosphorylated STAT3, suggesting that JAK/STAT activation can also occur through JAK2/TYK2 [30]. Remarkably, direct inhibition of phosphorylated STAT3 with Stattic resulted in reduced STAT3 and increased levels of phosphorylated Erk1/2 (Figure 6). This suggests that the stimulated proliferation rate of HL-1 cardiomyocytes is a balance between STAT3 signaling and MAPkinase signaling [31]. Although prolonged inhibition of one of the upstream or downstream of JAK/STAT or MAPK pathways lead to decreased proliferation rate of HL-1 cardiomyocytes either in the presence of mitogenic factors or conditioned medium of ADSC.

The therapeutic benefit of stem cells for cardiac therapy is well-accepted, however the stem cell response to the host 's post-MI microenvironment is uncertain [32].
The main mode of action of cardiac stem cell therapy is through paracrine mechanisms. Indeed, the intravenous administration of conditioned culture media from bone marrow derived MSC in pigs improved cardiac remodeling and perfusion [33,34]. To unravel the mechanism of paracrine therapeutic benefit of cardiac stem cell therapy, we subjected cardiomyocytes to the conditioned medium of ADSC.

\section{Conclusions}

The post-infarct cardiac microenvironment consists of an imbalanced level of inflammatory and anti-inflammatory mediators that correlate with the outcome of diseased myocardium. Cytokines might exert different function in time and dose dependent manner. Prolonged chronic high levels of IL-6 after MI are considered as a cause of hypertrophy and heart failure. Recent studies demonstrate that pro-inflammatory cytokines can activate cardioprotective signaling pathways in the post-infarct heart. IL-6 though might exert dynamic actions and act as a potent "myokine", where in a rapid response to acute myocardial infarction it activates cardioprotective pathways [35], resulting in increase in cardiomyocyte proliferation. Application of the conditioned medium derived from therapeutic cells rather than cells themselves would circumvent the problem of retention in cardiac stem cell therapy. Additionally, the current approach of use of primed conditioned medium of therapeutic stem cells offer "off the-shelf" product, which may be used for multiple injections.

\section{Competing interests}

The authors report that there is no conflict of interest associated with this paper.

\section{Authors' contributions}

EP carried out the experimental studies, drafted the graphs, performed the statistical analysis and wrote the paper. GK have been involved in the design of the study, drafting the manuscript and revising it critically. MGLB have been involved in the molecular genetic studies. $\mathrm{MCH}$ have been involved in revising critically the manuscript and have given final approval of the version to be published. All authors read and approved the final manuscript.

\section{Acknowledgments}

The authors gratefully acknowledge Anna Rita Bellu, Jojanneke Middeljans, Marije Bakker, Roland van Leeuwen, Klaas Sjollema and the financial support of the Translational Excellence in Regenerative Medicine (TeRM) SmartMix Program of the Netherlands Ministry of Economic Affairs and the Netherlands Ministry of Education, Culture and Science. This research was further supported by the Groningen University Institute Drug Exploration (GUIDE) of the University of Groningen and the University Medical Center Groningen and grants from the J.K. de Cock Foundation and the Netherlands Organisation for Scientific Research (NWO). G.K. is supported by the Netherlands Organization for Scientific Research and the Netherlands Organization for Health Research and Development (NOW/ZonMW \#916.11.022). M.C.H. is supported by the Groningen University Institue for Drug Exploration (GUIDE) and the W.J. Kolff Institute for Biomedical Materials Science and Application of the University of Groningen. Microscopical imaging was performed at the UMCG Imaging Center (UMIC), which is supported by the Netherlands Organisation for Health Research and Development (ZonMW grant 40-00506-98-9021). 
Received: 29 January 2013 Accepted: 5 February 2013

Published: 13 February 2013

\section{References}

1. Bergmann O, Bhardwaj RD, Bernard S, Zdunek S, Barnabe-Heider F, Walsh S, Zupicich J, Alkass K, Buchholz BA, Druid H, Jovinge S, Frisen J: Evidence for cardiomyocyte renewal in humans. Science 2009, 324:98-102.

2. Kajstura J, Rota M, Cappetta D, Ogorek B, Arranto C, Bai Y, Ferreira-Martins J, Signore S, Sanada F, Matsuda A, Kostyla J, Caballero MV, Fiorini C, D 'Alessandro DA, Michler RE, Del Monte F, Hosoda T, Perrella MA, Leri A, Buchholz BA, Loscalzo J, Anversa P: Cardiomyogenesis in the aging and failing human heart. Circulation 2012, 126:1869-1881.

3. Braun T, Dimmeler S: Breaking the silence: stimulating proliferation of adult cardiomyocytes. Dev Cell 2009, 17:151-153.

4. Angert D, Berretta RM, Kubo H, Zhang H, Chen X, Wang W, Ogorek B, Barbe $M$, Houser SR: Repair of the injured adult heart involves new myocytes potentially derived from resident cardiac stem cells. Circ Res 2011, 108:1226-1237.

5. Miettinen JA, Ylitalo KV, Niemela M, Kervinen $K$, Saily M, Koistinen $P$, Savolainen ER, Makikallio TH, Huikuri HV: Left ventricular functional recovery after intracoronary injection of autologous bone marrowderived stem cells in patients with acute myocardial infarction: a dose-response pilot study. Int J Cardiol 2011, 154:354-356.

6. Hwang $\mathrm{H}$, Kloner RA: Improving regenerating potential of the heart after myocardial infarction: factor-based approach. Life Sci 2010, 86:461-472.

7. Willems E, Lanier M, Forte E, Lo F, Cashman J, Mercola M: A chemical biology approach to myocardial regeneration. J Cardiovasc Trans/ Res 2011, 4:340-350.

8. Herrmann JL, Wang Y, Abarbanell AM, Weil BR, Tan J, Meldrum DR: Preconditioning mesenchymal stem cells with transforming growth factor-alpha improves mesenchymal stem cell-mediated cardioprotection. Shock 2010, 33:24-30

9. Herrmann $J L$, Weil BR, Abarbanell AM, Wang Y, Poynter JA, Manukyan MC, Meldrum DR: IL-6 and TGF-alpha costimulate mesenchymal stem cell vascular endothelial growth factor production by ERK-, JNK-, and PI3K-mediated mechanisms. Shock 2011, 35:512-516.

10. Luo Y, Wang Y, Poynter JA, Manukyan MC, Herrmann JL, Abarbanell AM, Weil BR, Meldrum DR: Pretreating mesenchymal stem cells with interleukin-1 beta and transforming growth factor-beta synergistically increases vascular endothelial growth factor production and improves mesenchymal stem cell-mediated myocardial protection after acute ischemia. Surgery 2011, 151:353-363.

11. Atsma DE, Fibbe WE, Rabelink TJ: Opportunities and challenges for mesenchymal stem cell-mediated heart repair. Curr Opin Lipidol 2007, 18:645-649.

12. Daher SR, Johnstone BH, Phinney DG, March KL: Adipose stromal/stem cells: basic and translational advances: the IFATS collection. Stem Cells 2008, 26:2664-2665.

13. Kilroy GE, Foster SJ, Wu X, Ruiz J, Sherwood S, Heifetz A, Ludlow JW, Stricker DM, Potiny S, Green P, Halvorsen YD, Cheatham B, Storms RW, Gimble JM: Cytokine profile of human adipose-derived stem cells: expression of angiogenic, hematopoietic, and pro-inflammatory factors. J Cell Physiol 2007, 212:702-709.

14. Efimenko Al, Starostina EE, Rubina KA, Kalinina NI, Parfenova EV: Viability and angiogenic activity of mesenchymal stromal cells from adipose tissue and bone marrow in hypoxia and inflammation in vitro. Tsitologiia 2010, 52:144-154.

15. Efimenko A, Starostina E, Kalinina N, Stolzing A: Angiogenic properties of aged adipose derived mesenchymal stem cells after hypoxic conditioning. J Trans/ Med 2011, 9:10.

16. Zhang DZ, Gai LY, Liu HW, Jin QH, Huang JH, Zhu XY: Transplantation of autologous adipose-derived stem cells ameliorates cardiac function in rabbits with myocardial infarction. Chin Med J (Engl) 2007, 120:300-307.

17. Yu LH, Kim MH, Park TH, Cha KS, Kim YD, Quan ML, Rho MS, Seo SY, Jung JS: Improvement of cardiac function and remodeling by transplanting adipose tissue-derived stromal cells into a mouse model of acute myocardial infarction. Int J Cardiol 2010, 139:166-172.

18. Matsushita K, Iwanaga S, Oda T, Kimura K, Shimada M, Sano M, Umezawa A, Hata J, Ogawa S: Interleukin-6/soluble interleukin-6 receptor complex reduces infarct size via inhibiting myocardial apoptosis. Lab Invest 2005, 85:1210-1223.
19. Waxman AB, Kolliputi N: IL-6 protects against hyperoxia-induced mitochondrial damage via $\mathrm{Bcl}$-2-induced Bak interactions with mitofusins. Am J Respir Cell Mol Biol 2009, 41:385-396.

20. Wuestefeld T, Klein C, Streetz KL, Betz U, Lauber J, Buer J, Manns MP, Mulle W, Trautwein C: Interleukin-6/glycoprotein 130-dependent pathways are protective during liver regeneration. J Biol Chem 2003, 278:11281-11288.

21. Blindenbacher A, Wang $X$, Langer I, Savino R, Terracciano L, Heim MH: Interleukin 6 is important for survival after partial hepatectomy in mice. Hepatology 2003, 38:674-682

22. German CL, Sauer BM, Howe CL: The STAT3 beacon: IL-6 recurrently activates STAT 3 from endosomal structures. Exp Cell Res 2011, 317:1955-1969.

23. Thangarajah H, Vial IN, Chang E, El-Ftesi S, Januszyk M, Chang El, Paterno J, Neofytou E, Longaker MT, Gurtner GC: IFATS collection: Adipose stromal cells adopt a proangiogenic phenotype under the influence of hypoxia. Stem Cells 2009, 27:266-274.

24. McKay BR, De Lisio M, Johnston AP, O 'Reilly CE, Phillips SM, Tarnopolsky MA, Parise G: Association of interleukin- 6 signalling with the muscle stem cell response following muscle-lengthening contractions in humans. PLoS One 2009, 4:e6027.

25. You L, Li L, Xu Q, Ren J, Zhang F: Postconditioning reduces infarct size and cardiac myocyte apoptosis via the opioid receptor and JAK-STAT signaling pathway. Mol Biol Rep 2011, 38:437-443.

26. Dawn B, Xuan YT, Guo Y, Rezazadeh A, Stein AB, Hunt G, Wu WJ, Tan W, Bolli R: IL-6 plays an obligatory role in late preconditioning via JAK-STAT signaling and upregulation of iNOS and COX-2. Cardiovasc Res 2004, 64:61-71.

27. Bersell K, Arab S, Haring B, Kuhn B: Neuregulin1/ErbB4 signaling induces cardiomyocyte proliferation and repair of heart injury. Cell 2009, 138:257-270.

28. leda M, Tsuchihashi T, Ivey KN, Ross RS, Hong TT, Shaw RM, Srivastava D: Cardiac fibroblasts regulate myocardial proliferation through beta1 integrin signaling. Dev Cell 2009, 16:233-244.

29. Novoyatleva T, Diehl F, van Amerongen MJ, Patra C, Ferrazzi F, Bellazzi R, Engel FB: TWEAK is a positive regulator of cardiomyocyte proliferation. Cardiovasc Res 2010, 85:681-690.

30. Firmbach-Kraft I, Byers M, Shows T, Dalla-Favera R, Krolewski JJ: Tyk2, Prototype of a novel class of Non-receptor tyrosine kinase genes. Oncogene 1990, 5:1329-1336.

31. Fischer $P$, Hilfiker-Kleiner D: Survival pathways in hypertrophy and heart failure: the gp130-STAT3 axis. Basic Res Cardiol 2007, 102:279-297.

32. Moonen JR, Harmsen MC, Krenning G: Cellular plasticity: the good, the bad, and the ugly? Microenvironmental influences on progenitor cell therapy. Can J Physiol Pharmacol 2012, 90:275-285.

33. Timmers L, Lim SK, Arslan F, Armstrong JS, Hoefer IE, Doevendans PA, Piek J, El Oakley RM, Choo A, Lee CN, Pasterkamp G, de Kleijn DP: Reduction of myocardial infarct size by human mesenchymal stem cell conditioned medium. Stem Cell Res 2007, 1:129-137.

34. Timmers L, Lim SK, Hoefer IE, Arslan F, Lai RC, van Oorschot AA, Goumans MJ, Strijder C, Sze SK, Choo A, Piek JJ, Doevendans PA, Pasterkamp G, de Kleijn DP: Human mesenchymal stem cell-conditioned medium improves cardiac function following myocardial infarction. Stem Cell Res 2011, 6:206-214.

35. Lecour S, James RW: When are pro-inflammatory cytokines SAFE in heart failure? Eur Heart J 2011, 32:680-685.

doi:10.1186/1479-5876-11-39

Cite this article as: Przybyt et al:: Adipose stromal cells primed with hypoxia and inflammation enhance cardiomyocyte proliferation rate in vitro through STAT3

and Erk1/2. Journal of Translational Medicine 2013 11:39. 